\title{
A NOVEL GEL ELECTROLYTE FOR VALVE-REGULATED LEAD ACID BATTERY
}

\author{
Metin GENÇTEN ${ }^{1,2}$, Koray B. DÖNMEZ ${ }^{3}$, Yücel ŞAHİN ${ }^{3, *}$ \\ ${ }^{1}$ Faculty of Science, Department of Chemistry, Anadolu University, 26470, Eskişehir, Turkey \\ ${ }^{2}$ Faculty of Arts\&Science, Department of Chemistry, Ordu University, 52200, Ordu, Turkey \\ ${ }^{3}$ Faculty of Arts\&Science, Department of Chemistry, Y1ld1z Technical University, 34210 Istanbul, Turkey
}

\begin{abstract}
A novel gel electrolyte system used in lead-acid batteries was investigated in this work. The gel systems were prepared by addition of different amount of $\mathrm{Al}_{2} \mathrm{O}_{3}, \mathrm{TiO}_{2}$ and $\mathrm{B}_{2} \mathrm{O}_{3}$ into the gelled system consisting of $6 \mathrm{wt} \%$ fumed silica and $30 \mathrm{wt} \%$ sulfuric acid solution for the first time. The anodic peak currents and peak redox capacities of the gel electrolytes were characterized by cyclic voltammetric method. When $\mathrm{B}_{2} \mathrm{O}_{3}$ and $\mathrm{Al}_{2} \mathrm{O}_{3}$ were used as additives in fumed silica based gel electrolyte system, the anodic peak currents and peak redox capacities decreased. However, the investigated parameters in cyclic voltammetry (anodic peak current and capacities) increased by the adding of $3.0 \mathrm{wt} \%$ of $\mathrm{TiO}_{2}$ in the fumed silica based gel system. The solution and charge transfer resistances of the gel electrolytes were investigated by electrochemical impedance spectroscopy. While the solution resistances were lower in gel systems having different amount additives than pure fumed silica based gel, the charge transfer resistance was the lowest in gel electrolytes consisting fumed silica and fumed silica- $\mathrm{TiO}_{2}$. The morphological differences of gelled systems were elucidated by scanning electron microscopic and optic microscopic analysis. The battery performances were studied by obtaining discharge curves of prepared gel electrolytes. The performance of gelled systems were higher than that of non-gelled electrolyte at room temperature. The mixture of fumed silica- $\mathrm{TiO}_{2}$ was suggested an alternative gel formulation for gel valve-regulated lead acid batteries. $\mathrm{TiO}_{2}$ can be a useful additive for gel-VRLA batteries.
\end{abstract}

Keywords: Lead acid battery, Fumed silica, Gel electrolyte, Additives, Battery test

\section{INTRODUCTION}

Valve regulated lead acid (VRLA) batteries have been used for several applications in industry due to their advantages such as high power density, good performance under deep-discharge conditions, no water or electrolyte addition (maintenance free), low internal resistance, long service life, high current density, operating in a range temperature conditions, good resistant to vibration in applications [1-6]. Since application areas of the VRLA batteries are extensive and energy is the most critical issue of the world, many important studies have been performed to improve capacity and cyclic life of these battery systems $[7,8]$. In previous studies, effects of the electrolyte material and its composition on the battery performance have been investigated mainly due to the critical role of the electrolyte $[4,9,10$ $13]$.

In lead acid batteries, two main approaches have been employed to immobilize the sulfuric acid electrolyte such as gelled electrolyte and absorptive glass mat (AGM) systems. In the AGM system, sulfuric acid is soaked into a kind of glass mat and this mat separator is used as matrix for electrolyte. In the gelled electrolyte system, silica sols, colloidal silica, fumed silica and some organic siloxane have been used to obtain a three dimensional network gel which absorbs sulfuric acid [4, 8, 11-17].

In the gelled electrolyte systems, the type of gelling agents determines the viscosity, agitation time, chemical structure of the gel, etc.. Most of the studies were focused on fumed silica based gel electrolyte systems because of the advantages of fumed silica such as high capacity, high stability and good thixotropy $[11,15]$. Fumed silica is often used as a gel agent for gel VRLA batteries. When 
fumed silica is hydrolyzed in sulfuric acid solution, isolated silanol groups combine to each other and they form a gel structure. It is mixed with optimum concentration of sulfuric acid solutions to obtain the gel electrolyte. Although hydroxylation of fumed silica forms gelled electrolyte, gels should still exhibit some mechanical parameters such as stability, good three dimensional network, etc. for high performance of the batteries [12]. The properties of gelled electrolyte affect the electrolyte filling process and performance of gel valve-regulated lead-acid (VRLA) batteries directly. In previous work, some additives were added into the electrolyte to improve the gel electrolyte system. Vinod et al. reported that the addition of phosphoric acid decreased the rate of oxygen evolution reaction [18]. Tantichanakul et al. improved the discharge capacity of VRLA batteries by adding of vanaline in gelled system [11]. Performance effects of sodium sulfate and magnesium sulfate were studied in our previous study and these sulfate salts combined well with gelled system [15]. All of these studies show that good combination of additives with gelled agents has a great potential to improve the capacity, cyclic life and structure of gelled VRLA batteries. However, most of additives used of these studies are soluble in electrolyte solution, some insoluble oxides such as $\mathrm{Al}_{2} \mathrm{O}_{3}$ and $\mathrm{TiO}_{2}$ can bring a new approach for formation of a good gel structure. The inorganic additives can be combine with hydrolyzed silica particles and it can improve the structure of three dimensional network of gel system. The cyclic life and performance of VRLA batteries can show better performance in the wellconstructed gel structure. Besides, boron oxide, which is soluble in sulfuric acid solution, can affect the conductivity of fumed silica based gel electrolyte systems.

The aim of this study is to investigate the performance of the gel electrolyte system by addition of varying amount of some additives such as $\mathrm{Al}_{2} \mathrm{O}_{3}, \mathrm{~B}_{2} \mathrm{O}_{3}$ and $\mathrm{TiO}_{2}$ during the formation of fumed silica based gel electrolyte. Cyclic voltammetric (CV) and electrochemical impedance spectroscopic (EIS) methods were used to determine the effects of additives on performance of fumed silica based gel systems. Discharge curves of prepared gel systems were also obtained for the optimum electrolyte formulations. Morphologies of gel electrolyte systems were examined by scanning electron microscope (SEM) and optical microscope.

\section{EXPERIMENTAL}

\subsection{Preparation of Electrolytes}

The electrolytes were prepared with sulfuric acid solution (J. T. Baker wt\% 95-97) and fumed silica (Sigma-Aldrich, $7 \mathrm{~nm}$, St. Louis, USA). Concentration of sulfuric acid and fumed silica are the key parameters to affect the performance and capacity of VRLA batteries $[15,19,20]$. The optimum amount of sulfuric acid and fumed silica those were determined in our previous study as $30 \mathrm{wt} \%$ and 6 wt\%, respectively, were used in this study [15]. In order to investigate the effect of inorganic additives, $\mathrm{Al}_{2} \mathrm{O}_{3}$ (Sigma-Aldrich, $\geq 98 \%$, St. Louis, USA), $\mathrm{B}_{2} \mathrm{O}_{3}$ (Sigma-Aldrich, $\geq 99 \%$, St. Louis, USA) and $\mathrm{TiO}_{2}$ (Sigma-Aldrich, $\geq 99 \%$, St. Louis, USA) were added into the electrolyte. The gel electrolyte systems were prepared by mixing of $6 \mathrm{wt} \%$ fumed silica, $30 \mathrm{wt} \%$ sulfuric acid solution and the additives in four different amounts such as 1.5, 3.0, 4.5 and $6.0 \mathrm{wt} \% \quad(0.02,0.04,0.06$ and 0.08 $\mathrm{g} / \mathrm{mL}$ ). Mechanical dispersion of the mixtures (gel electrolyte systems) was achieved by stirring the electrolyte system at $500 \mathrm{rpm}$ for 30 minutes as reported in our previous work [15].

\subsection{Electrochemical Experiments}

Three electrode systems were used for all cyclic voltammetric (CV) and electrochemical impedance spectroscopic measurements (EIS). Before each measurements, the working and counter electrodes were polished and then the working electrode was polarized at $-1.4 \mathrm{~V}$ versus $\mathrm{Hg} / \mathrm{Hg}_{2} \mathrm{SO}_{4}, \mathrm{~K}_{2} \mathrm{SO}_{4}$ (saturated) (mercury sulfate electrode) to remove impurities. Cyclic voltammetry and electrochemical impedance measurements were carried out in gel electrolyte systems using lead working (area $0.5 \mathrm{~cm}^{2}$ ) and lead counter (area $0.6 \mathrm{~cm}^{2}$ ) electrodes with $\mathrm{Hg} / \mathrm{Hg}_{2} \mathrm{SO}_{4}, \mathrm{~K}_{2} \mathrm{SO}_{4}$ (saturated) reference electrode 
(MSE). Cyclic voltammetric experiments were performed between -1.4 and $-0.8 \mathrm{~V}$ versus $\mathrm{Hg} / \mathrm{Hg}_{2} \mathrm{SO}_{4}$ at a $20 \mathrm{mV} \cdot \mathrm{s}^{-1} \mathrm{scan}$ rate at room temperature. All the electrochemical experiments were carried out using a CHI Potentiostat/Galvanostat model 660D (CH Instruments, USA).

Electrochemical impedance spectroscopy experiments were performed with conventional three electrode system at open circuit potential over a $10^{5}-10^{-2} \mathrm{~Hz}$ frequency range at an amplitude of 10 $\mathrm{mV}$ and the Figure 1 shows an equivalent circuit model which was used at fitting process for each impedance spectrum $[12,15]$.

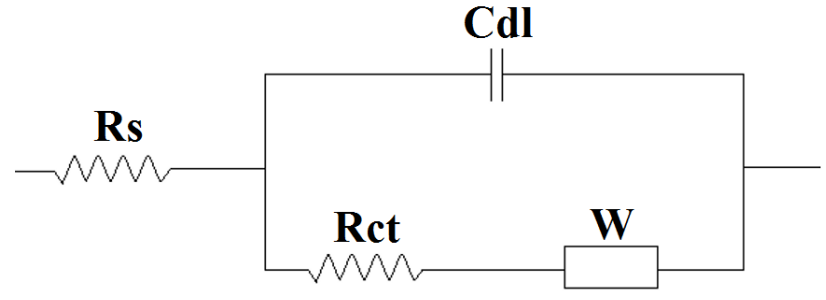

Figure 1. Equivalent circuit model

\subsection{Battery Test}

Discharge curves of the gelled electrolyte systems were obtained for the first cyclic with Reference 3000 series Gamry instrumentation (Gamry, USA). One positive $\left(\mathrm{PbO}_{2}\right)$ and two negative $(\mathrm{Pb})$ electrodes were used in one cell of a lead acid battery and separated by micro-porous membrane. The dimension of each electrode was $2.5 \times 3 \mathrm{~cm}$. The electrodes were located with $0.5 \mathrm{~cm}$ spacing. Battery systems were charged and discharged with constant currents at 0.025 and $0.01 \mathrm{~A}$, respectively. All experiments were conducted between 1.75 and $2.15 \mathrm{~V}$.

\subsection{Scanning Electron Microscopic and Stereo Microscopy}

SEM pictures of gel systems were taken with $1000 \times$ magnification after dried under vacuum. The gelled systems were coated with $\mathrm{Au}$ in 30 seconds at $40 \mathrm{~mA}$. The structural features of lead electrolytes were examined with field emission scanning electron microscope using Carl Zeiss Ultra Plus FESEM. Micrographs of the gel electrolytes were obtained by using Olympus BX-51TF stereo microscope with $20 \times$ magnitude. The micrographs were taken from gel with additives that was placed on a lam.

\section{RESULTS AND DISCUSSION}

\subsection{Effect of $\mathrm{Al}_{2} \mathrm{O}_{3}$}

$\mathrm{Al}_{2} \mathrm{O}_{3}$ (alumina) was used as an electrolyte additive to improve the performance of the batteries. Cyclic voltammetric and electrochemical impedance spectroscopic methods were performed to investigate the effects of $\mathrm{Al}_{2} \mathrm{O}_{3}$ additives on the gel system. Different amounts of $\mathrm{Al}_{2} \mathrm{O}_{3}$ were added into gel system consisting of $6 \mathrm{wt} \%$ fumed silica and $30 \mathrm{wt} \%$ sulfuric acid.

The cyclic voltammograms of the gel systems consisting of fumed silica, sulfuric acid and alumina are shown in Figure 2a. The anodic and cathodic peaks obtained between $-1.10-(-0.9) \mathrm{V}$, represents the formation of lead sulfate from metallic lead and metallic lead from lead sulfate, respectively [21-23]. Here, we have investigated the formation of lead sulfate in cyclic voltammetric studies. The anodic peak currents and anodic peak redox capacities of the gel systems are illustrated in Figure $2 \mathrm{~b}$. According to the cyclic voltammograms, the anodic peak currents and the anodic peak redox capacities of the gel systems consisting of alumina were lower than the gel system consisting of $6 \mathrm{wt} \%$ 
fumed silica and sulfuric acid. The second highest value of the anodic peak current and anodic peak redox capacity were determined by the addition of 4.5 and $6.0 \mathrm{wt} \%$ of $\mathrm{Al}_{2} \mathrm{O}_{3}$ into the fumed silica based gel system, respectively. The deformation of gel structure may cause a radical decreasing of anodic peak current intensities and redox peak capacities by the addition of $\mathrm{Al}_{2} \mathrm{O}_{3}$. Since the diffusion of mobile ions to electrode surface occurred harder in alumina including deformed gel structure, the interactions of electrodes and electrolyte decreased. This also decreased the anodic peak currents and capacities as the given reaction in Eq. 1.

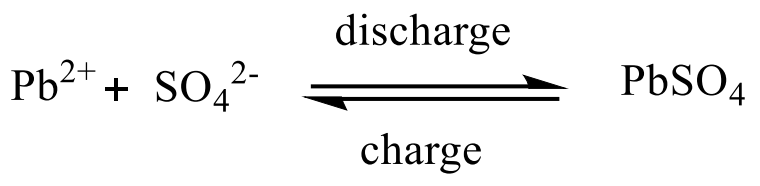

Figure $2 \mathrm{c}$ shows the electrochemical impedance spectra of the gel electrolyte systems having fumed silica and $\mathrm{Al}_{2} \mathrm{O}_{3}$. The open circuit potential was about $-0.995 \mathrm{~V}$ in each spectrum and they were fitted well by the equivalent circuit of Figure 1. Nyquist plots show a high frequency semi-circle and low frequency line for spectrums. Here, Rs, Rct, Cdl and W represent the solution resistance, charge transfer resistance, double layer capacitance and Warburg impedance, respectively. Solution resistance (Rs) is related the ohmic resistance consisting of the resistance of the electrolyte, the resistance of the corrosion products placed on the surface of electrode, and the resistance of the electrical connections to the electrode. Rct shows the charge transfer resistance of the rate-controlling electrochemical reaction of corrosion process [15, 24-26]. Our previous works showed that when the concentration of fumed silica increased in the sulfuric acid solutions, the anodic peak currents and peak redox capacities decreased and the resistance of solution (Rs) increased with charge transfer resistance (Rct) [15]. However, the Rs and Rct values didn't change regularly with increasing amount of $\mathrm{Al}_{2} \mathrm{O}_{3}$ into gel system consisting of fumed silica and sulfuric acid solution (Figure 2d). Rs values of prepared gel systems decreased by the adding of $\mathrm{Al}_{2} \mathrm{O}_{3}$ into the fumed silica based gel system. Since the $\mathrm{Al}_{2} \mathrm{O}_{3}$ may affect the amount of electrolyte (sulfuric acid) in the three-dimensional gel system, the amount of free ions $\left(\mathrm{H}^{+}, \mathrm{SO}_{4}{ }^{2-}\right)$ in the gel electrolyte and the conductivity of gel electrolyte increased. Moreover, Rct values were also increased in gelled system due to $\mathrm{Al}_{2} \mathrm{O}_{3}$ not combined well with the isolated silanol groups of fumed silica and web structure of the gelled system. This result may also be caused by the distribution of the different amount of alumina in the three-dimensional gel system. According to the electrochemical characterization, performance of the gel system was affected negatively by the addition of alumina.

Figure 3 shows the stereo microscopic photograph and SEM images of the gelled and non-gelled systems for fumed silica- $\mathrm{Al}_{2} \mathrm{O}_{3}$ mixture. The solid particles of $\mathrm{Al}_{2} \mathrm{O}_{3}$ can be seen easily in Figure $3 \mathrm{a}$. When the sulfuric acid solution was added into the mixture containing fumed silica and alumina, the electrolyte system was obtained and alumina was dispersed homogeneously as shown in Figure $3 \mathrm{~b}$. The structure of fumed silica based gel system deformed when the $\mathrm{Al}_{2} \mathrm{O}_{3}$ was added as additive in electrolyte system. The deformed structure of fumed silica based gel system was seen in Figure 3c. 
(a)

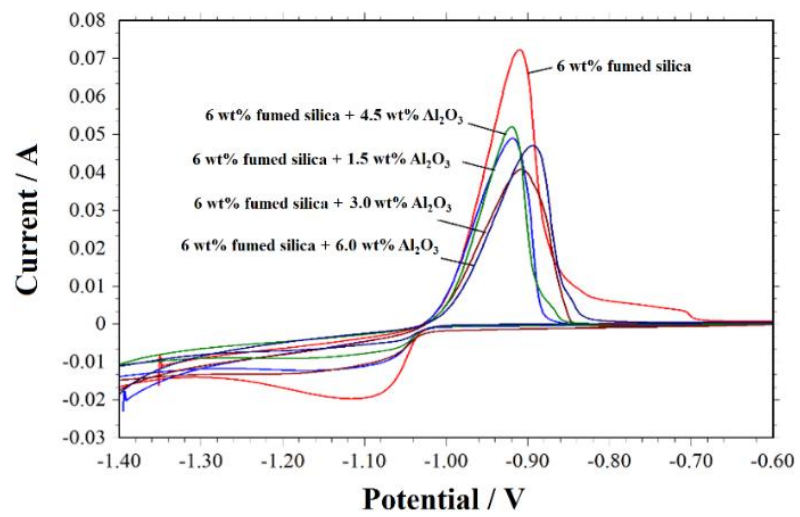

(c)

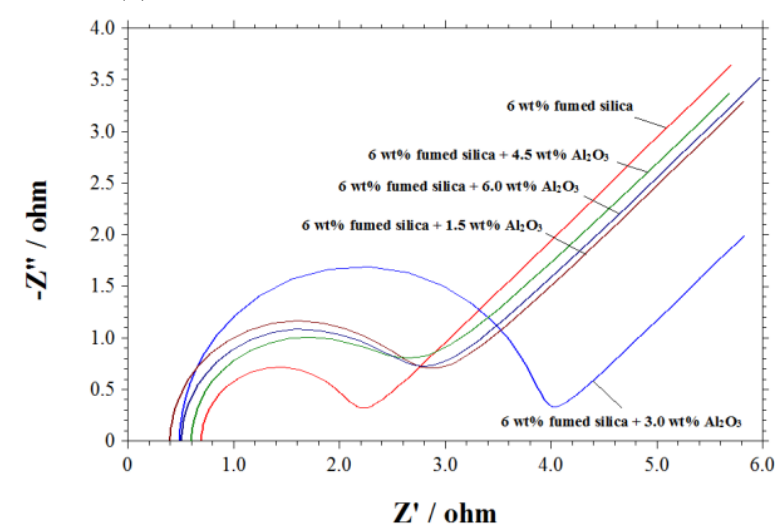

(b)

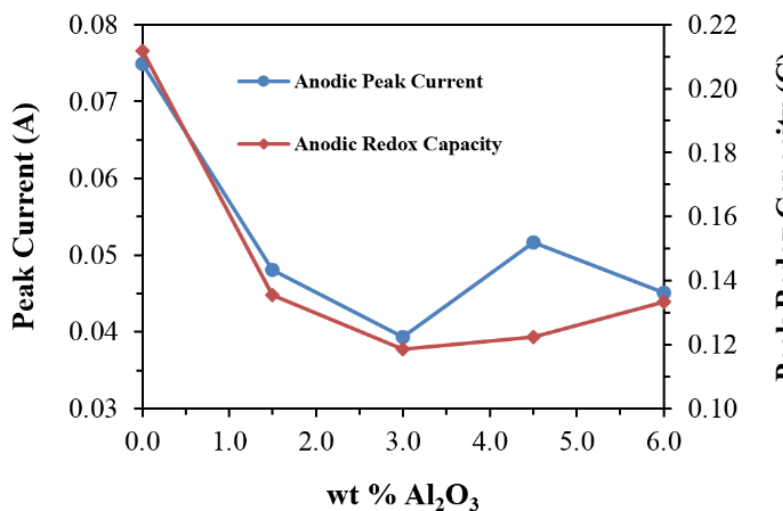

(d)

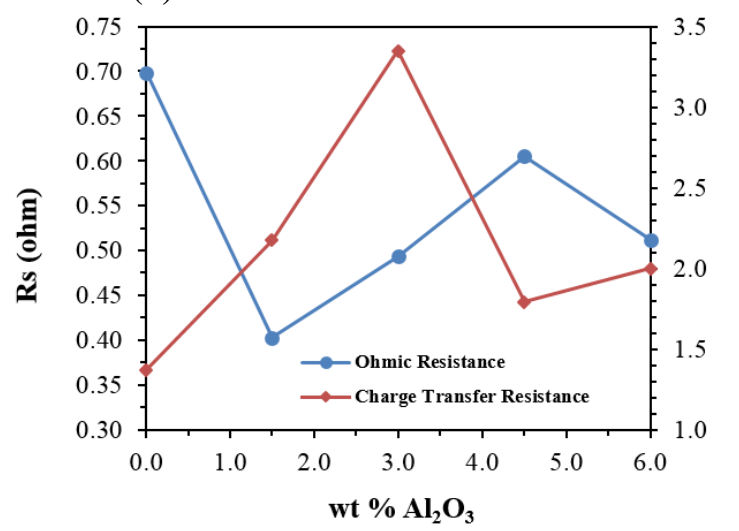

Figure 2. Cyclic voltammetric and electrochemical impedimetric behaviors of gel electrolytes having fumed silica- $\mathrm{Al}_{2} \mathrm{O}_{3}$ and sulfuric acid solutions a cyclic voltammograms $\mathbf{b}$ the anodic peak capacities and currents $\mathbf{c}$ impedance spectra and $\mathbf{d}$ Rs and Rct values

(a)

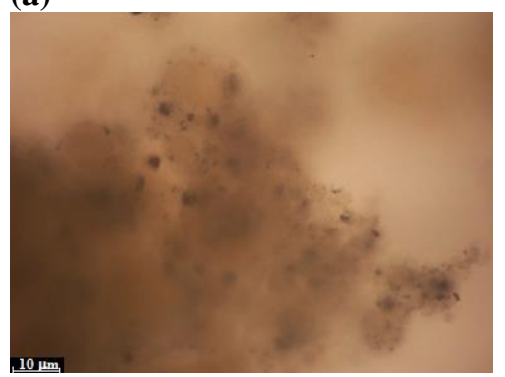

(b)

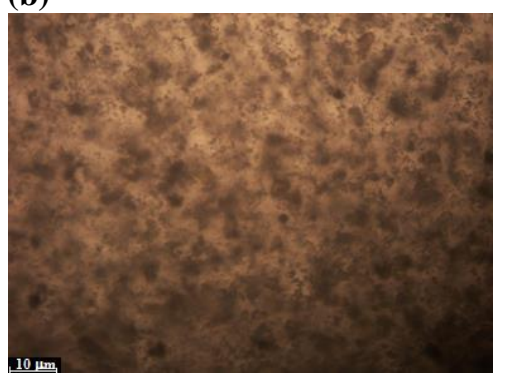

(c)

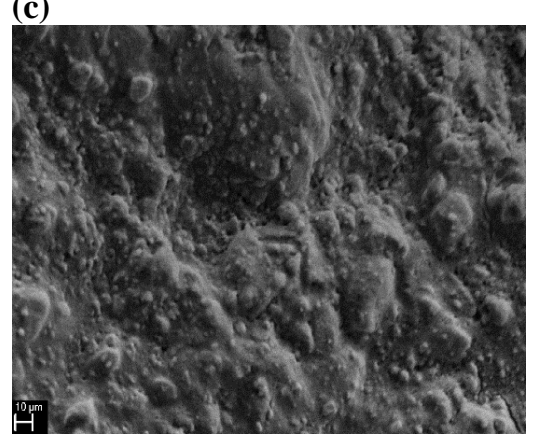

Figure 3. Stereo microscopic photograph of fumed silica- $\mathrm{Al}_{2} \mathrm{O}_{3}$ mixture a before gelation $\mathbf{b}$ after gelation; SEM pictures of fumed silica- $\mathrm{Al}_{2} \mathrm{O}_{3}$ mixture $\mathbf{c}$ after gelation 


\subsection{Effect of $\mathrm{B}_{2} \mathrm{O}_{3}$}

To determine the effect of $\mathrm{B}_{2} \mathrm{O}_{3}$ on the performance of the fumed silica gel system, different amounts of $\mathrm{B}_{2} \mathrm{O}_{3}$ were added into the fumed silica gel system having $6 \mathrm{wt} \%$ fumed silica and $30 \mathrm{wt} \%$ sulfuric acid. Cyclic voltammograms and electrochemical impedance spectroscopy were taken for the fumed silica gel system after addition of varying amounts of $\mathrm{B}_{2} \mathrm{O}_{3}(1.5-6.0 \mathrm{wt} \%)$. The results are presented in Figure 4. The viscosity of the fumed silica gel system decreased by increasing amounts of $\mathrm{B}_{2} \mathrm{O}_{3}$. According to the results, the anodic peak currents and anodic redox capacities did not change linearly with the increasing amounts of $\mathrm{B}_{2} \mathrm{O}_{3}$. Since the boron oxide was completely dissolved in the gel system, the conductivity of the gel system was affected by the addition of different amount of $\mathrm{B}_{2} \mathrm{O}_{3}$. The three dimensional web structure of the fumed silica based gel system was also affected negatively by the addition of $\mathrm{B}_{2} \mathrm{O}_{3}$. Since the reaction rate between lead and sulfate (Eq. 1) decreased, anodic redox capacity and peak current intensity decreased which were lower than the results obtained from the fumed silica based gelled system due to deformation of gel (Figure 4a and 4b). The anodic peak currents showed a liner decrease with increasing amount of boron oxide. This gives information about the reaction rate between lead and sulfate and it occurs slower by the adding of $\mathrm{B}_{2} \mathrm{O}_{3}$ into fumed silica based gel system $[3,13,15]$. Although the determined anodic peak redox capacities didn't show a liner decrease, they had lower value than that of fumed silica based gel electrolyte system. This result may also be caused with deformed structure of gel system.

Figure $4 \mathrm{c}$ shows the electrochemical spectra of $\mathrm{B}_{2} \mathrm{O}_{3}$ including fumed silica based gel systems. Rs values of $\mathrm{B}_{2} \mathrm{O}_{3}$ added gel systems were lower than fumed silica based gel electrolyte, which was expected. When boron oxide was dissolved into gel system, the amount of free ions increased in electrolyte system. Since amount of free ions increased into the gel, the solution resistance showed a sharp decrease (Figure 4d). However, Rs value was started to increase in the gel system consisting 4.5 $\mathrm{wt} \%$ of $\mathrm{B}_{2} \mathrm{O}_{3}$ (Figure $4 \mathrm{~d}$ ). Its reason can be explained with that the higher ion concentration than optimum value of additive in the gel system increases the solution resistance due to limited mobility of free ions [15]. Rct values of $\mathrm{B}_{2} \mathrm{O}_{3}$ including gel systems were higher than fumed silica based gel electrolyte system (Figure 4d). In this situation, the transfer of electrons with electrode surface and electrolyte occurred slower. Rct values increased since interactions between of free space of electrode and dissolved boron oxide instead of sulfate ions. The lowest Rct was determined for fumed silica based gel electrolyte system (Figure 4d). Obtained results by electrochemical impedance spectroscopic analysis were very compatible with cyclic voltammetric analysis (Figure 4a). The performance of gel electrolyte was also affected negatively by adding of boron oxide.

The three dimensional gel structure of system changed radically by the addition of boron oxide into the fumed silica based gel system since it is soluble in acidic solution. Figure 5 shows the gelled and non-gelled electrolyte systems. It can be seen from the pictures, the three dimensional network couldn't be obtained in the $\mathrm{B}_{2} \mathrm{O}_{3}$ including gel system (Figure $5 \mathrm{~b}$ and $5 \mathrm{c}$ ). Because of this result, the anodic peak currents and capacities of gelled system consisting of boron oxide as additive in fumed silica based gel were lower than the gelled system having pure fumed silica and sulfuric acid (Figure $4 b)$. 
(a)

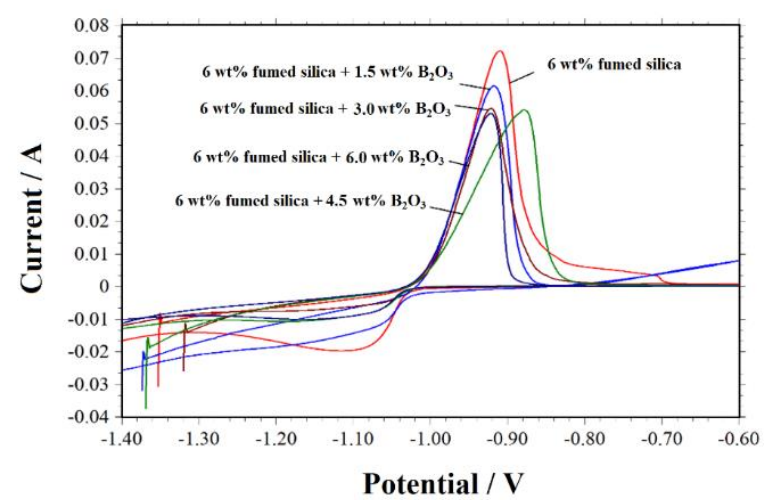

(c)

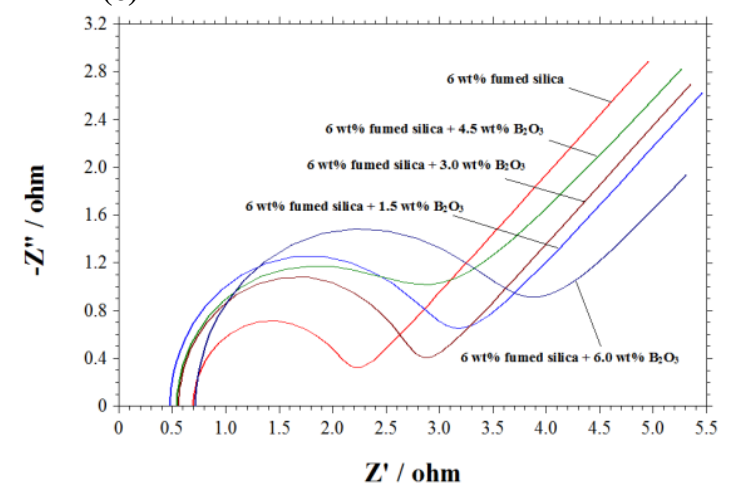

(b)

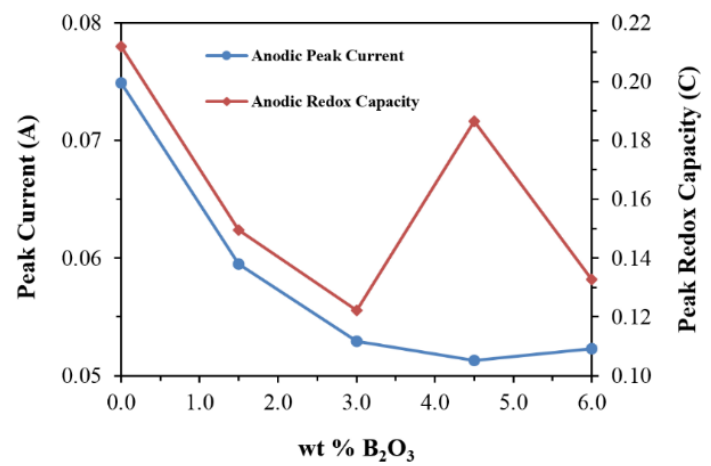

(d)

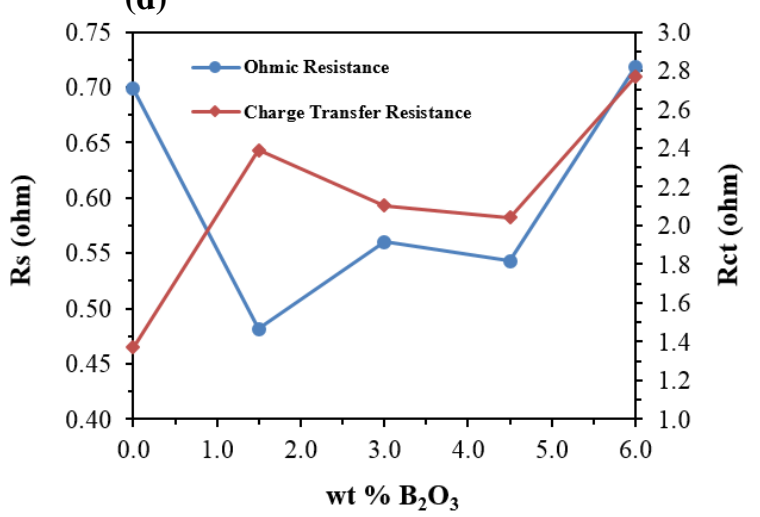

Figure 4. Cyclic voltammetric and electrochemical impedimetric behaviors of gel electrolytes having fumed silica- $\mathrm{B}_{2} \mathrm{O}_{3}$ and sulfuric acid solutions a cyclic voltammograms $\mathbf{b}$ the anodic peak capacities and currents $\mathbf{c}$ impedance spectra and $\mathbf{d}$ Rs and Rct values

(a)

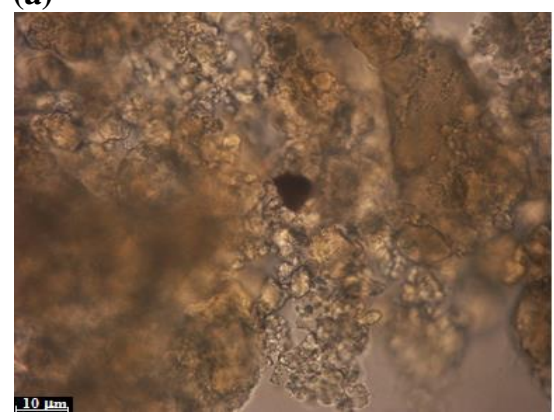

(b)

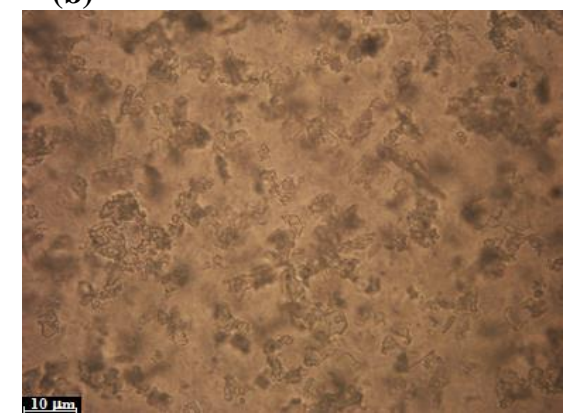

(c)

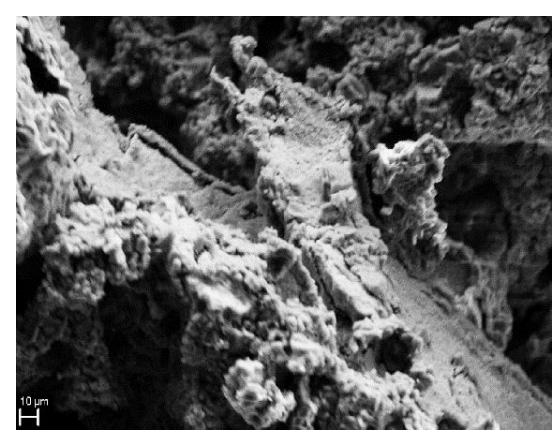

Figure 5. Stereo microscopic photograph of fumed silica- $\mathrm{B}_{2} \mathrm{O}_{3}$ mixture a before gelation $\mathbf{b}$ after gelation; SEM pictures of fumed silica- $\mathrm{B}_{2} \mathrm{O}_{3}$ mixture $\mathbf{c}$ after gelation 


\subsection{Effect of $\mathrm{TiO}_{2}$}

Titanium (IV) oxide was added into the gel system having $6 \mathrm{wt} \%$ fumed silica and $30 \mathrm{wt} \%$ sulfuric acid solution to investigate the effect of $\mathrm{TiO}_{2}$ on the performance of the gel electrolyte. The gel system was characterized with cyclic voltammetric (CV) and electrochemical impedance spectroscopic methods (CV, EIS). The viscosity of the gel increased by the addition of $\mathrm{TiO}_{2}$.

Figure 6a shows the cyclic voltammograms of the gel electrolyte consisting of fumed silica and $\mathrm{TiO}_{2}$. The highest value of anodic peak redox capacity and peak current was obtained in the gel system consisting of $3.0 \%$ of $\mathrm{TiO}_{2}$. Since the reaction between electrode surface and electrolyte ions occurred easier in this concentration than others, the anodic peak currents and peak redox capacities increased (Figure 6b). These parameters were determined lower in gel system consisting of higher or lower concentration of $3.0 \mathrm{wt} \%$ of titanium (IV) oxide (Figure 6b). The anodic peak currents and redox capacities of the gel system having fumed silica and $\mathrm{TiO}_{2}$ were similar to the fumed silica gel system. The reason of this result can be explained with the three dimensional structure of the gel system. Titanium (IV) oxide created a network with silanol groups and the electrolyte was absorbed into the free space of the system.

The electrochemical impedance spectra of $\mathrm{TiO}_{2}$ added fumed silica based gel electrolytes were shown in Figure 6c. The solution resistance of gel systems decreased to gel system consisting of $3.0 \mathrm{wt} \%$ of $\mathrm{TiO}_{2}$. When the gel system had higher or lower concentration of $3.0 \mathrm{wt} \%$ of $\mathrm{TiO}_{2}$, Rs values increased (Figure 6d). Rs values are related with conductivity of gel electrolyte and the mobility of free ions. Since the interactions of gel agents $\left(\mathrm{SiO}_{2}, \mathrm{TiO}_{2}\right)$ created a well-constructed gel structure, solution resistance showed a certain decrease to the gel system consisting of $3.0 \mathrm{wt} \%$ of $\mathrm{TiO}_{2}$ (Figure 6d). Furthermore, Rct value was the lowest in this $\mathrm{TiO}_{2}$ concentration (Figure 6d). The reaction between sulfate ions and pure lead occur easier when the good gel structure is formed [15]. This also supported the formation of a good gel structure in this amount of $\mathrm{TiO}_{2}$ with fumed silica. Rs and Rct values determined by impedance analysis were very compatible with the cyclic voltammetric studies.

The stereo microscopic pictures and SEM pictures of the fumed silica and fumed silica- $\mathrm{TiO}_{2}$ mixtures were shown in Figure 7. The picture of the gelled and non-gelled systems demonstrates that $\mathrm{TiO}_{2}$ combined well with isolated silanol groups. Three dimensional gel structure and network were obtained by the interactions of isolated silanol groups and hydrolysed $\mathrm{TiO}_{2}$ molecules (Figure $7 \mathrm{~b}$ and 7d). The gel electrolyte having fumed silica- $\mathrm{TiO}_{2}$ behaviours like fumed silica based gel system due to well-constructed network. The electrochemical data supported this good combination between the hydrolysed $\mathrm{SiO}_{2}$ and $\mathrm{TiO}_{2}$ particles in sulfuric acid solution (Figure $6 \mathrm{~b}$ and $6 \mathrm{~d}$ ). The pore sizes of fumed silica based gel electrolyte system was lower than that of $\mathrm{TiO}_{2}$ including gel electrolyte (Fig. 7c and 7d). This result may be related with interactions of two different gel agents, which have different particle sizes, in gel system consisting of fumed silica- $\mathrm{TiO}_{2}$. The bigger pore size for gelled system can increase the diffusion of mobile ions to electrode surface [27]. Raghavan et al. showed possible gel structure of silica particles [28]. According to the information about the interaction of silica particles, a possible interaction of silanol groups and hydrolysed $\mathrm{TiO}_{2}$ particles to obtain a wellconstructed gel structure can be drawn in Figure 8. A plausible reaction mechanism can be purposed in Figure 9. 
(a)

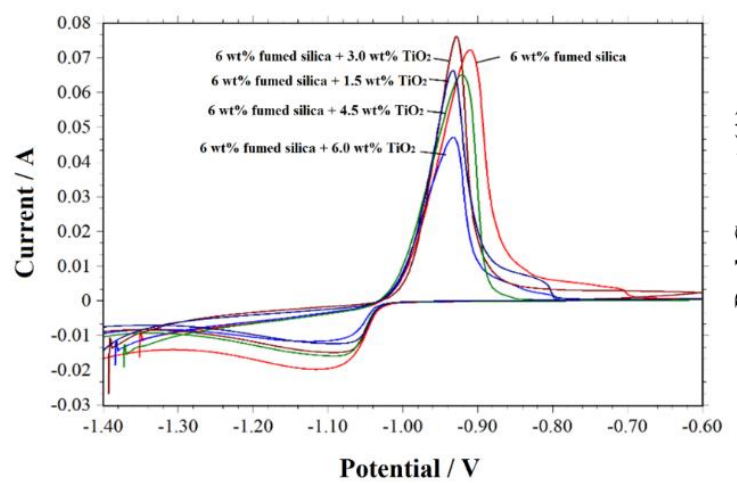

(c)

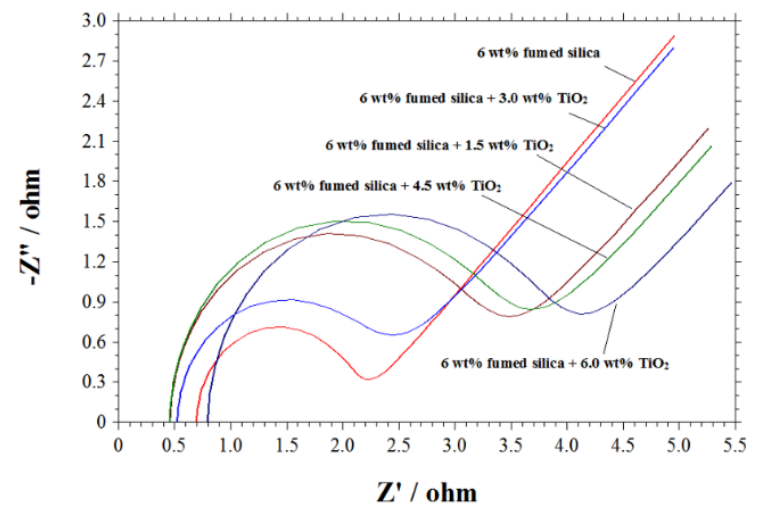

(b)

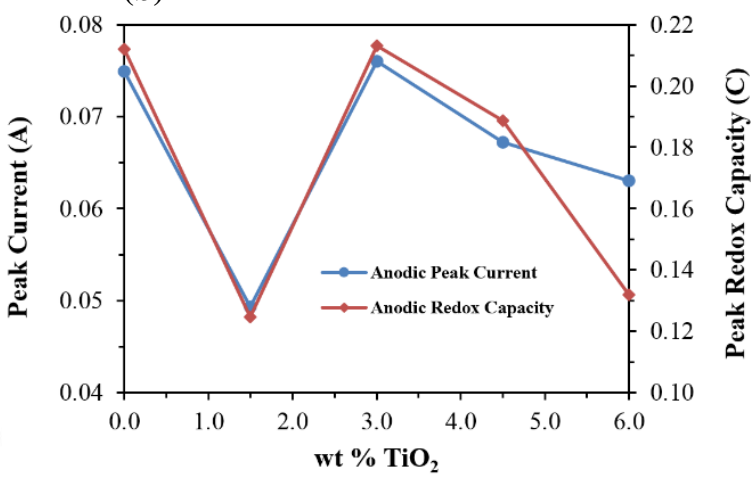

(d)

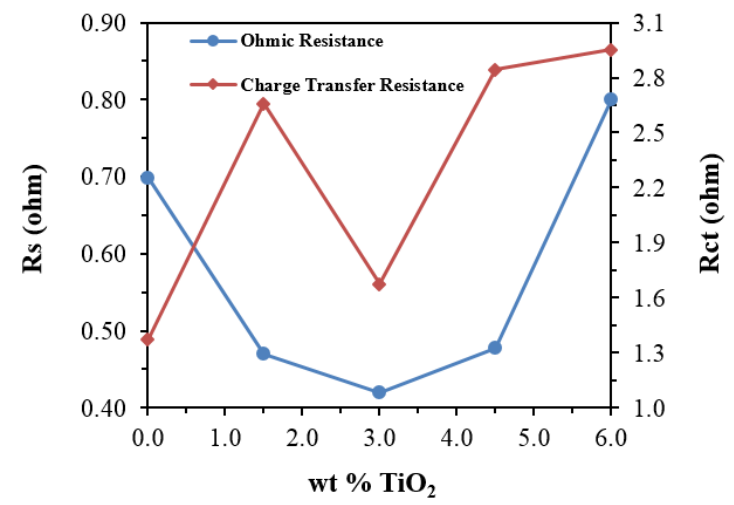

Figure 6. Cyclic voltammetric and electrochemical impedimetric behaviors of gel electrolytes having fumed silica- $\mathrm{TiO}_{2}$ and sulfuric acid solutions a cyclic voltammograms $\mathbf{b}$ the anodic peak capacities and currents $\mathbf{c}$ impedance spectra and $\mathbf{d}$ Rs and Rct values 
(a)

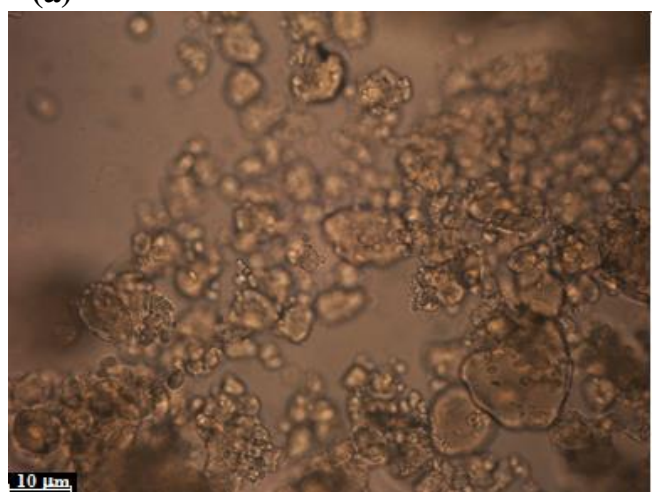

(c)

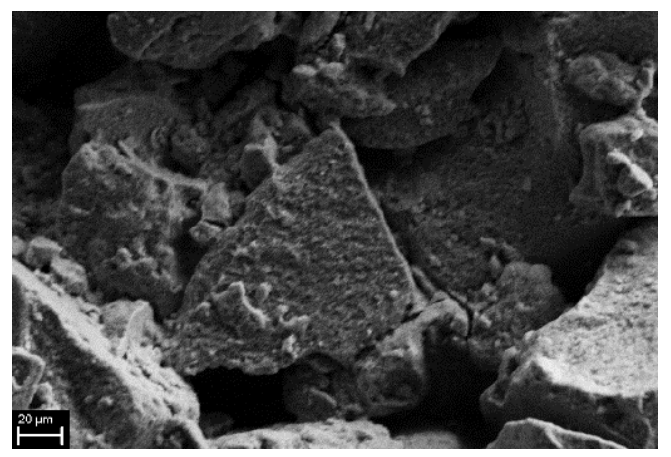

(b)

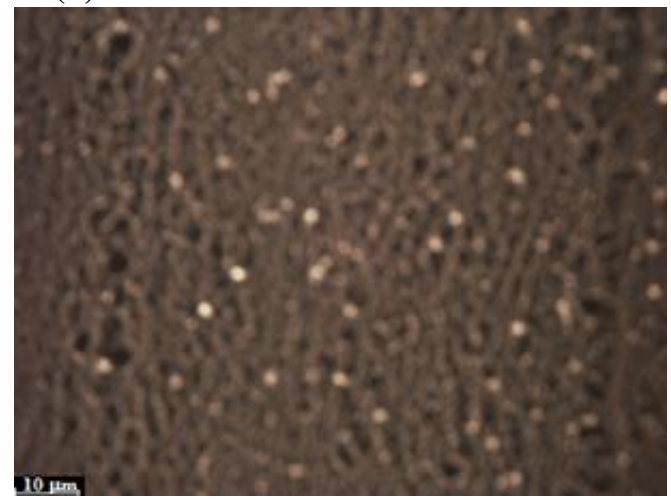

(d)

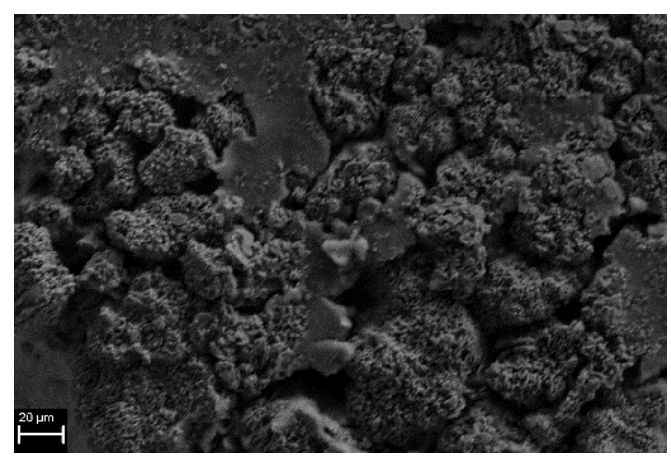

Figure 7. Stereo microscopic photograph of fumed silica- $\mathrm{TiO}_{2}$ mixture a before gelation $\mathbf{b}$ after gelation; SEM pictures of electrolyte after gelation $\mathbf{c}$ fumed silica $\mathbf{d}$ fumed silica- $\mathrm{TiO}_{2}$ mixture

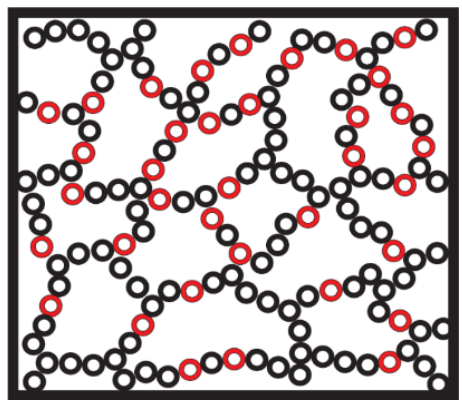

Figure 8. The possible interactions of silanol groups and hydrolyzed $\mathrm{TiO}_{2}$ particles; Red: $\mathrm{TiO}_{2}, \mathrm{Black}$ $\mathrm{SiO}_{2}$ 

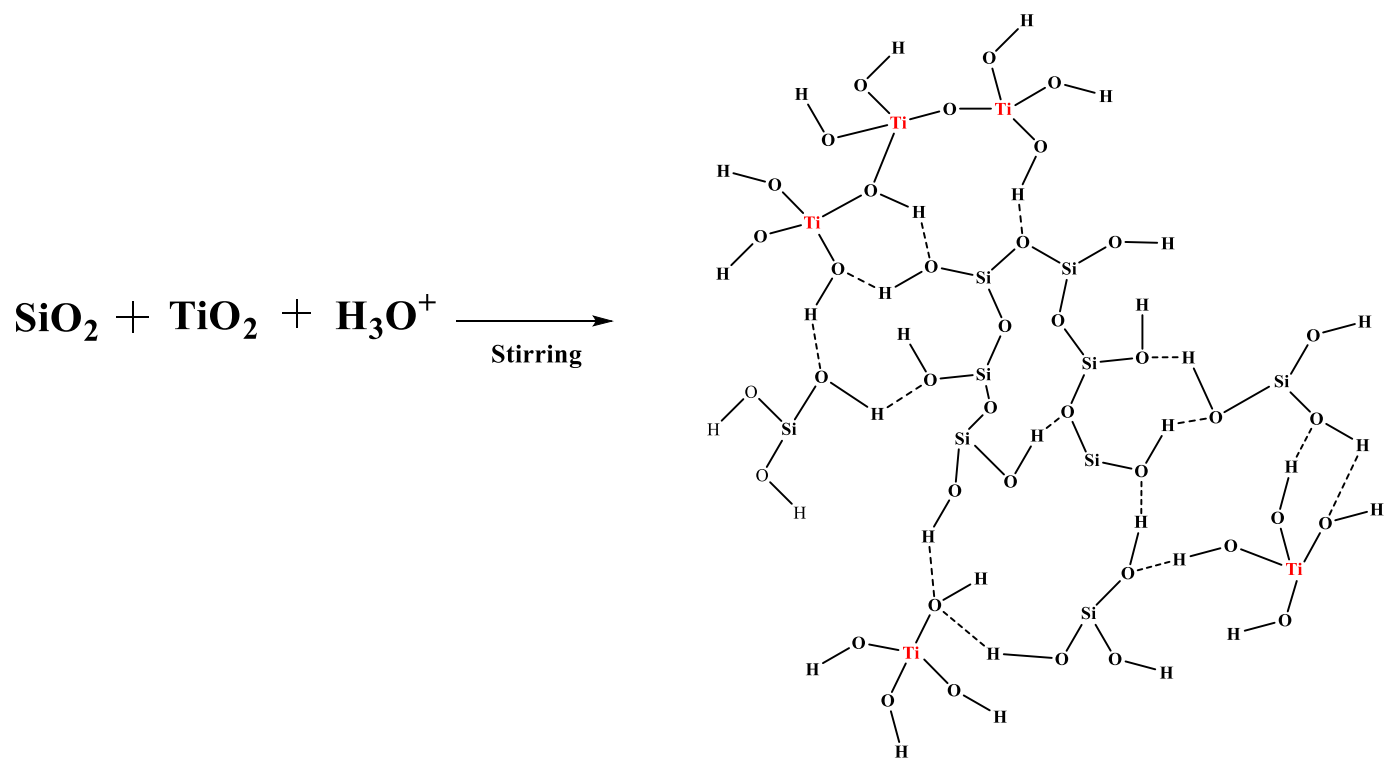

Formed gel system with hydrolyzed $\mathrm{SiO}_{2}-\mathrm{TiO}_{2}$

Figure 9. A plausible reaction between hydrolysed $\mathrm{SiO}_{2}-\mathrm{TiO}_{2}$

\subsection{Battery Test}

The discharge curves were obtained for chosen gel formulations according to the results of electrochemical studies. Figure 10 shows the discharge curves of the fumed silica based gel electrolytes. Gel systems showed better discharge performance than that of non-gelled electrolyte consisting of $30 \mathrm{wt} \%$ sulfuric acid solution. The discharge behaviors of gelled systems consisting of fumed silica- $\mathrm{B}_{2} \mathrm{O}_{3}$ and fumed silica- $\mathrm{Al}_{2} \mathrm{O}_{3}$ were not good as expected to the results of cyclic voltammetric and electrochemical impedimetric studies. However, $\mathrm{TiO}_{2}$ including fumed silica based gel system had good discharge behaviors than others. Besides, the potential, at which discharging of batteries were started, was the highest for the fumed silica- $\mathrm{TiO}_{2}$ based gel system (Figure 10). Since $\mathrm{TiO}_{2}$ had similar physical properties with fumed silica such as oxidation states, melting point, density and etc., the electrolyte system consisting of fumed silica- $\mathrm{TiO}_{2}$ showed better discharge behavior than the other gel formulations (fumed silica- $\mathrm{Al}_{2} \mathrm{O}_{3},-\mathrm{B}_{2} \mathrm{O}_{3}$ ). In the gelled system consisting of fumed silica and $\mathrm{TiO}_{2}$, the three dimensional gel structures were obtained through molecular interactions between hydrolyzed $\mathrm{SiO}_{2}$ and $\mathrm{TiO}_{2}$ groups. These interactions ensure formation of a web structure which adjust surface reactions between electrodes and electrolyte. Therefore, the sulfation of the electrodes slowly occurs in this three dimensional gelled system (Figure 7b). The discharge time of fumed silica and fumed silica- $\mathrm{TiO}_{2}$ based gel system almost same about 450 seconds for studied conditions (Table 1). The discharge capacity of fumed silica and fumed silica- $\mathrm{TiO}_{2}$ based gel electrolyte almost same about $3 \mathrm{mAh}$ (Table 1). According to the results, fumed silica- $\mathrm{TiO}_{2}$ based gel electrolyte system can be suggested as an alternative for pure fumed silica based gel system. 


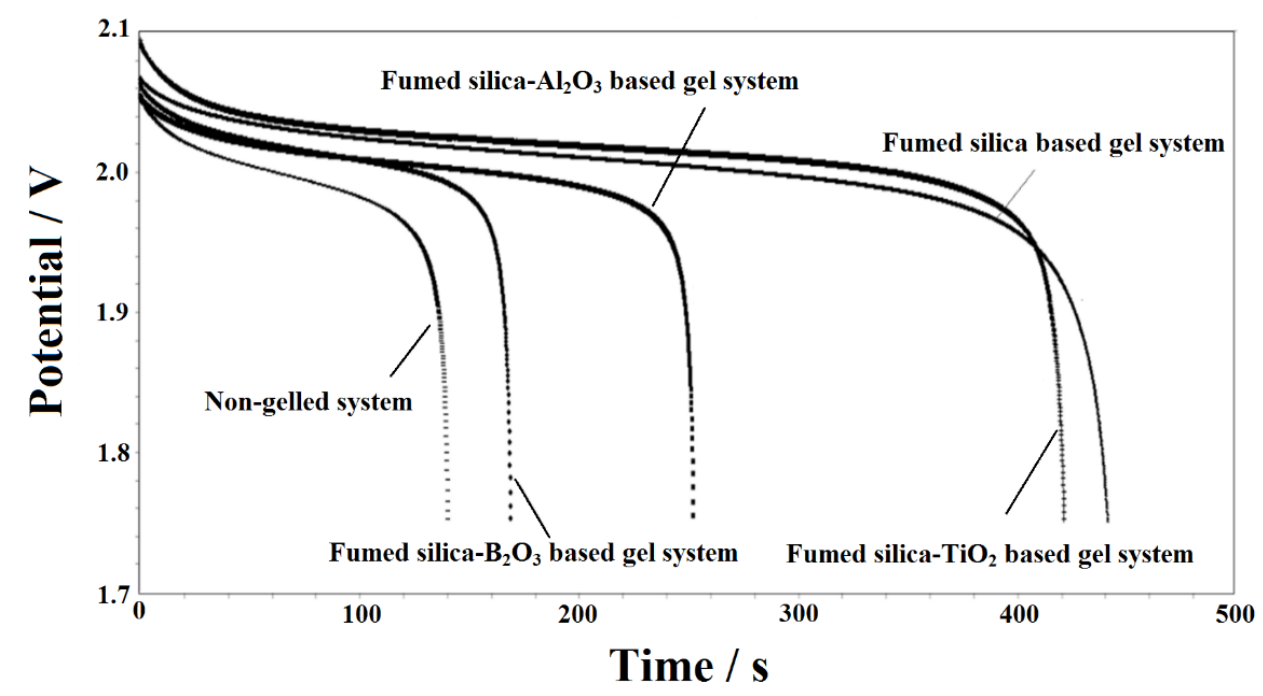

Figure 10. The discharge curves of gel electrolytes consisting of $6 \mathrm{wt} \%$ fumed silica and $30 \mathrm{wt} \%$ sulfuric acid; $6 \mathrm{wt} \%$ fumed silica, $\mathrm{Al}_{2} \mathrm{O}_{3}$ and $30 \mathrm{wt} \%$ sulfuric acid; $6 \mathrm{wt} \%$ fumed silica, $\mathrm{TiO}_{2}$ and $30 \mathrm{wt} \%$ sulfuric acid; $6 \mathrm{wt} \%$ fumed silica, $\mathrm{B}_{2} \mathrm{O}_{3}$ and $30 \mathrm{wt} \%$ sulfuric acid; 30 wt\% sulfuric acid (non-gelled system)

Table 1. Discharge time and capacities of gelled systems and non-gelled system

\begin{tabular}{ccc}
\hline Electrolyte & Discharge time (s) & Discharge capacity (mAh) \\
\hline $\begin{array}{c}\text { Non-gelled } \\
\text { system }\end{array}$ & 140 & 0.80 \\
$\begin{array}{c}\text { Fumed silica- } \mathrm{B}_{2} \mathrm{O}_{3} \\
\text { based gel system }\end{array}$ & 170 & 0.95 \\
$\begin{array}{c}\text { Fumed silica- } \mathrm{Al}_{2} \mathrm{O}_{3} \\
\text { based gel system }\end{array}$ & 250 & 1.20 \\
$\begin{array}{c}\text { Fumed silica-TiO } \\
\text { based gel system }\end{array}$ & 420 & 3.00 \\
$\begin{array}{c}\text { Fumed silica based } \\
\text { gel system }\end{array}$ & 440 & 3.02 \\
\hline
\end{tabular}

\section{CONCLUSION}

Additives are important to improve the capacity and discharge behaviors of gel systems for VRLA batteries. In this study, the effects of some oxides were investigated for fumed silica based gel electrolyte system. In this concept, different amount of some oxides such as $\mathrm{TiO}_{2}, \mathrm{Al}_{2} \mathrm{O}_{3}$ and $\mathrm{B}_{2} \mathrm{O}_{3}$ were mixed with $6 \mathrm{wt} \%$ fumed silica gel system. According to the result of electrochemical studies (CV and EIS), each additive showed different behaviors for the gel electrolyte. The viscosity of the gel decreased due to dissolution of boron oxide in acidic media. This dissolution affected the anodic peak currents and redox capacity values negatively. However, the change of these parameters was not occurred parallel with the amount of boron oxide. This result also can be explained by deforming three dimensional structure of fumed silica based gel. When the $\mathrm{Al}_{2} \mathrm{O}_{3}$ was added into the gel electrolyte, the anodic peak current and peak redox capacity decreased radically. Since $\mathrm{Al}_{2} \mathrm{O}_{3}$ did not coordinate well with isolated silanol groups, the three dimensional network of fumed silica based gel system decreased. The last additive was $\mathrm{TiO}_{2}$. Different amount of $\mathrm{TiO}_{2}$ was added into the fumed silica based gel electrolyte and this gel system showed different electrochemical behaviors than the gel systems consisting of other additives. The reason of these differences could be explained by the structure of titanium (IV) oxide. $\mathrm{TiO}_{2}$ has the same physical properties with fumed silica. They formed a three dimensional network. The electrolyte was absorbed well by this system. When the amount $\mathrm{TiO}_{2}$ was 
wt\% 3.0 in the fumed silica based gel system, the anodic peak current and peak redox capacities were almost similar with fumed silica gel system. According to the results of obtained discharge behaviors of gelled electrolyte, the discharge capacity of $\mathrm{TiO}_{2}$ including gel system was higher than other gel electrolyte which were including $\mathrm{Al}_{2} \mathrm{O}_{3}$ and $\mathrm{B}_{2} \mathrm{O}_{3}$.

Since the VRLA batteries have been used in a lot of industrial branch, improving the capacity and the performance of this system is really important to decrease the cost of it. $\mathrm{TiO}_{2}$ including fumed silica based gel electrolyte can be used as an alternative gel formulation for VRLA batteries.

\section{ACKNOWLEDGEMENTS}

This work was supported by the SAN-TEZ program (No. 00897.STZ.2011-1) of Ministry of Science, Industry and Technology, Republic of Turkey, with Anadolu University, and Ericsson Turkey. Y. Şahin thanks to Prof. Dr. Kadir Pekmez, Prof. Dr. Ender Suvacı and Oktay Uysal for their supports to this study. M. Gençten thanks to TUBİTAK-BİDEB.

\section{REFERENCES}

[1] Ohmae T, Sawai K, Shiomi M, Osumi S. Advanced technologies in VRLA batteries for automotive applications. J Power Sources 2006; 154: 523-529.

[2] Tsujikawa T, Matsushima, T. Remote monitoring of VRLA batteries for telecommunications systems. J Power Sources 2007, 168: 99-104.

[3] Chang Y, Mao X, Zhao Y, Feng S, Chen H, Finlow D. Lead-acid battery use in the development of renewable energy systems in China. J Power Sources 2009; 191: 176-183.

[4] Lambert D.W. H, Greenwood P. H. J, Reed M. C. Advances in gelled-electrolyte technology for valve-regulated lead-acid batteries. J Power Sources 2002; 107: 173-179.

[5] Wagner R. High-power lead-acid batteries for different applications. J Power Sources 2005; 144: 494-504.

[6] May G. J, Calasanzio D, Aliberti R. VRLA automotive batteries for stop\&go and dual battery systems. J Power Sources 2005; 144: 411-417.

[7] Clement N. Use of synthetic fibre reinforcement for improving the performance of AGM separators for VRLA batteries. J. Power Sources 2004; 133: 87-93.

[8] Prengamani, R. D. Improvements to active material for VRLA batteries. J Power Sources 2005; 144: 426-437.

[9] Martha S.K, Hariprakash B, Gaffoor S.A, Ambalavanan S, Shukla A.K. Performance characteristics of a gelled-electrolyte valve-regulated lead-acid battery. Bull Mater Sci 2003; 26:465-469.

[10] Bhattacharya A, Basumallick I. N. Effect of mixed additives on lead-acid battery electrolyte. J Power Sources 2003; 113: 382-387.

[11] Tantichanakul T, Chailapakul O, Tantavichet N. Influence of fumed silica and additives on the gel formation and performance of gel valve-regulated lead-acid batteries. J Ind Eng Chem 2013; 19: 2085-2091. 
[12] Chen M.Q, Chen H. Y, Shu D, Li A.J, Finlow D.E. Effects of preparation condition and particle size distribution on fumed silica gel valve-regulated lead-acid batteries performance. J Power Sources 2008; 181: 161-171.

[13] Chen M, Guo W, Zhang M, Cheng F, Liu P, Cai Z, Zhang Y. Effect of polyols on the electrochemical behavior of gel valve-regulated lead-acid batteries. Electrochim Acta 2015; 164:243251.

[14] Pan K, Shi G, Li A, Li H, Zhao R, Wang F, Zhang W, Chen Q, Chen H, Xiong Z, Finlow D. The performance of a silica-based mixed gel electrolyte in lead acid batteries. J Power Sources 2012; 209: 262-268.

[15] Gençten M, Dönmez K.B, Şahin Y, Pekmez K, Suvacı E. Voltammetric and electrochemical impedimetric behavior of silica-based gel electrolyte for valve-regulated lead-acid battery. J Solid State Electrochem 2014; 18: 2569-2579.

[16] Gençten M, Dönmez K.B, Şahin Y. Investigation of the temperature effect on electrochemical behaviors of $\mathrm{TiO} 2$ for gel type valve regulated lead-acid batteries. Anadolu Univ J Sci Technology AAppl Sci Eng 2016; 17: 882-884

[17] Dönmez K.B, Gençten M, Şahin Y. A novel polysiloxane-based polymer as a gel agent for gelVRLA batteries. Ionics DOI no. 10.1007/s11581-017-2040-y

[18] Vinod M.P, Vijayamohanan K, Joshi S.N. Effect of silicate and phosphate additives on the kinetics of the oxygen evolution reaction in valve-regulated lead/acid batteries. J Power Sources 1998; 70:103-105.

[19] He L, Liu H, Wang Q, Chen H, Ren A, Hu J. Effects of covalently bonded siloxane on the electrochemical and physical behaviour of GEL-VRLA battery. J Electrochim Acta 2010; 56: 663-666.

[20] Bullock K.R, Trischan C.M, Burrow R.G. Photoelectrochemical and microprobe laser Raman studies of lead corrosion in sulfuric acid. J Electrochem Soc 1983; 130: 1283-1289.

[21] Pavlov D, Naidenov V, Ruevski S. Influence of $\mathrm{H}_{2} \mathrm{SO}_{4}$ concentration on lead-acid battery performance: H-type and P-type batteries. J Power Sources 2006; 161: 658-665.

[22] Pavlov D, Petkov G, Rogachev T. Influence of $\mathrm{H}_{2} \mathrm{SO}_{4}$ concentration on the performance of leadacid battery negative plates. J Power Sources 2008; 175: 586-594.

[23] Hamenoja E, Laitinen T, Sundholm G, Yli-Pentti A. The growth of oxide layers on lead and its alloys at a constant potential in the $\mathrm{PbO}_{2}$ potential region at different temperatures. Electrochim Acta 1989; 34: 233-241.

[24] Wu L, Chen H.Y, Jiang X. Effect of silica soot on behaviour of negative electrode in lead-acid batteries. J Power Sources 2002; 107: 162-166.

[25] Vinod M.P, Vijayamohanan K. Effect of gelling on the impedance parameters of $\mathrm{Pb} / \mathrm{PbSO}_{4}$ electrode in maintenance-free lead-acid batteries. J Power Sources 2000; 89: 88-92.

[26] Gençten M, Gürsu H, Şahin Y. Electrochemical investigation of the effects of V(V) and sulfuric acid concentrations on positive electrolyte for vanadium redox flow battery. Int $\mathbf{J}$ Hydrogen Energ 2016; 41: 9868-9875. 
Gençten et al. / Anadolu Univ. J. of Sci. and Technology A-Appl. Sci. and Eng. 18 (1) - 2017

[27] Sun X., Zhao J. Concentration optimization of fumed silica as gelator in lead-acid batteries. Electrochemistry 2016; 84: 578-584.

[28] Raghavan S.R, Walls H.J, Khan S.A. Rheology of silica dispersions in organic liquids: new evidence for solvation forces dictated by hydrogen bonding. Langmuir 2000; 16:7920-7930. 